\title{
Oral Spindle Cell Carcinoma -Diagnosis Based on Immunohistochemical Interpretation
}

\author{
Syeda Asiya Butool ${ }^{1, *}$, Ankit Natani ${ }^{2}$, Betina Chandolia ${ }^{3}$, Manas Bajpai ${ }^{4}$ \\ ${ }^{1}$ Department of Conservative Dentistry and Endodontics, NIMS University, Shoba Nagar, Jaipur, India. \\ ${ }^{2}$ Department of Pedodontics and Preventive Dentistry, NIMS University, Shoba Nagar, Jaipur, India. \\ ${ }^{3}$ Department of Oral and Maxillofacial Pathology, Daswani Dental College, Kota, Rajasthan, India. \\ ${ }^{4}$ Department of Oral and Maxillofacial Pathology, NIMS University, Shoba Nagar, Jaipur, India.
}

\begin{abstract}
Spindle Cell Carcinoma (SpCC) is a biphasic tumor. They are proven to be monoclonal dedifferentiated forms of conventional squamous carcinomas. It is a rare tumor which is infrequently observed in head, neck and in the aerodigestive tract. The tumor is aggressive and shows high frequency of recurrence and metastasis. It is an aggressive variant of squamous cell carcinoma which resembles a true sarcoma. It is a proliferation of spindle cells and squamous cells. For confirmation of diagnosis, immunohistochemistry is used. A Rare case of spindle cell squamous cell carcinoma in a 61 years old male in the tongue.The patient reported of rapidly growing lesion from six months with pain severe pain, dysphagia and difficulty in swallowing patient had history of chewing tobacco from past 35 years.
\end{abstract}

Keywords: Spindle Cell Variant, Biphasic tumor, Head and Neck, Pseudocarcinoma, Sqamous cell, Dysplastic.

\section{INTRODUCTION}

The WHO has classified spindle cell carcinoma as a variant of squamous cell carcinomas and is tagged as sarcomatoid squamous cell carcinoma. The synonyms and terms of this variant is used as pseudocarcinoma, polypoid squamous cell carcinoma, pleomorphic carcinoma, carcinosarcoma.

SCC of the head and neck is a rare variant [1]. It is most commonly reported in larynx followed by different mucosal sites such as gingiva, tongue, nasal cavity, oral cavity, and hypopharynx [2]. Squamous Cell Carcinoma is one of the malignant tumors, out of which Spindle cell variant (Sarcomatoid) of Squamous Cell Carcinoma is its highly aggressive variant. It is a biphasic tumor a neoplasm which is composed of epithelial squamous cells and mesenchymal spindle cells with sarcomatous appearance [3]. The tumor has a higher prevalence in males affecting primarily in fifth, sixth decades of life. This tumor is rare in occurrence and comprise of only 1 percent of tumors of oral cavity and most commonly occur on alveolar mucosa, buccal mucosa, tongue and lower lip. It is essential to accurately diagnose these tumors as the clinical management and outcome varies accordingly [4]. We report a case of Spindle Cell variant of Squamous Cell Carcinoma in a 61 year Old male in tongue.

\section{CASE REPORT}

A 61 year old male reported to NIMS Dental College with a

*Address correspondence to this author at the Department of Conservative Dentistry and Endodontics, NIMS University, Shoba Nagar, Jaipur, India. Email: asiyabutoo1786@gmail.com chief complaint of discomfort due to growth on the lateral surface of the tongue since one year. The patient was facing difficulty in eating food and even the speech was getting affected. The patient had a habit of chewing tobacco since last 35 years.

On Inspection, a mass was observed of about the size of $3 \mathrm{~cm}$ $\mathrm{x} 2 \mathrm{~cm}$ on the left lateral side of tongue (Fig. 1). The mass was firm in consistency and tender. There was no regional lymphadenopathy or any history of tumor before. Patient was advised routine investigations along with OPG and CT scan.

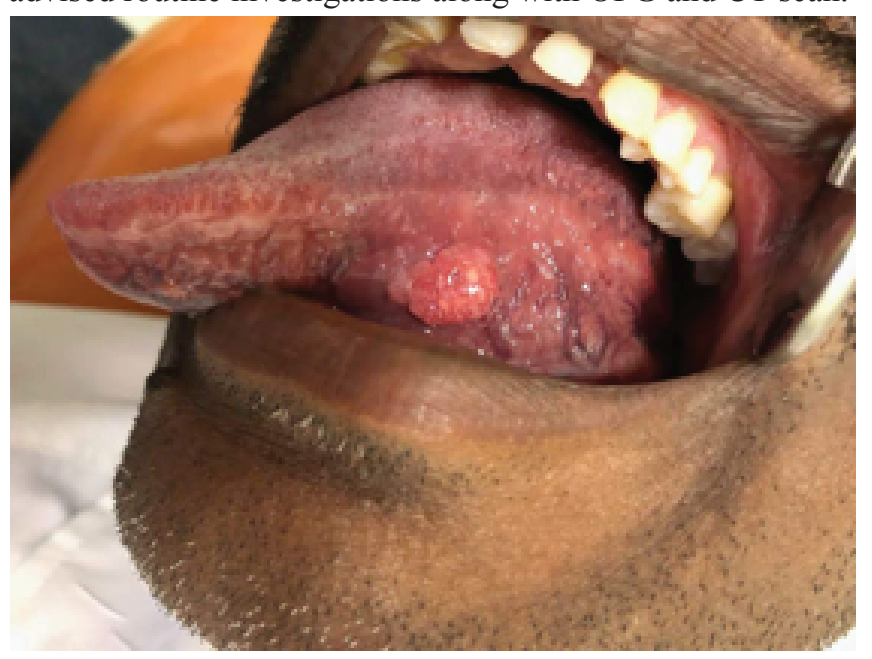

Fig. (1). Lesion on the Left Lateral Border of the Tongue.

The patient's consent was taken. The complete mass was excised. A sample was sent to the Department of Oral and 
Maxillofacial Pathology for microscopic evaluation. The gross specimen was firm in consistency. On microscopic examination, the tumor showed various patterns of spindle cells in fascicles, storiform like pattern along with inflammatory cells. Few dysplastic spindle cells were seen along with hyalinization at few areas. Along with spindle cells, epithelioid cells were also observed in some areas (Fig. 2). The tumor was provisionally diagnosed as Spindle Cell Variant of Squamous Cell Carcinoma.

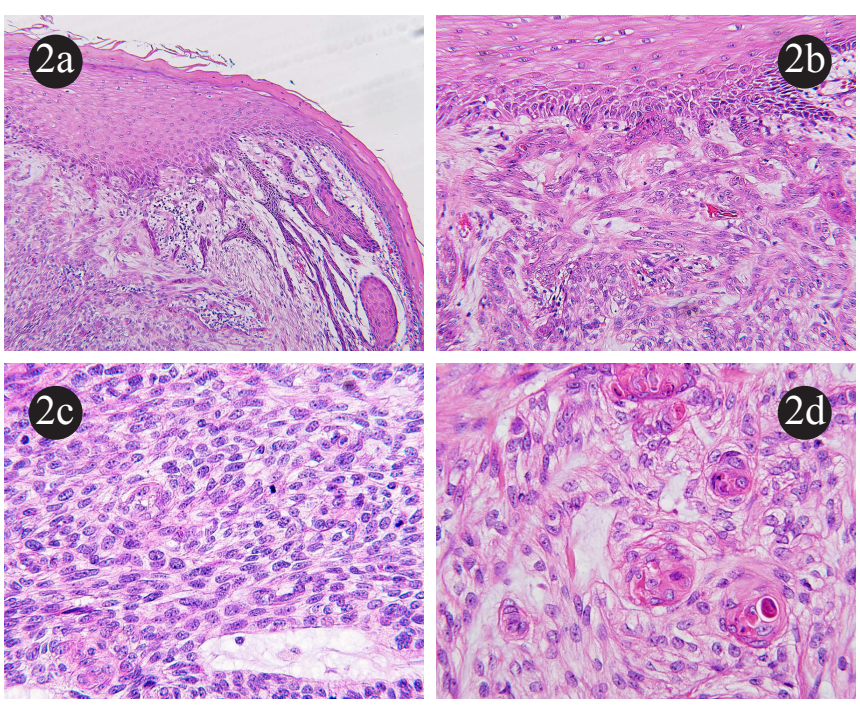

Fig. (2). (2a) Highly Dysplastic Epithelial Cells Invading the Stroma of Connective Tissue (X $20 \mathrm{H}$ and E Stain) (2b) loose myxofibrous stroma composed of both epithelial and spindle shaped cells (X $40 \mathrm{H}$ and E Stain) (2c) dense sheet of spindle shaped cells (X $40 \mathrm{H}$ and E Stain) (2d) Connective tissue stroma shows areas of keratinization in the form of keratin pearls. (X $40 \mathrm{H}$ and E Stain).

The tissue was then sent for immunohistochemistry which was found immunopositive for Cytokeratin AE1/AF3, Vimentin and p40. It was immunonegative for CD34 (Fig. 3).
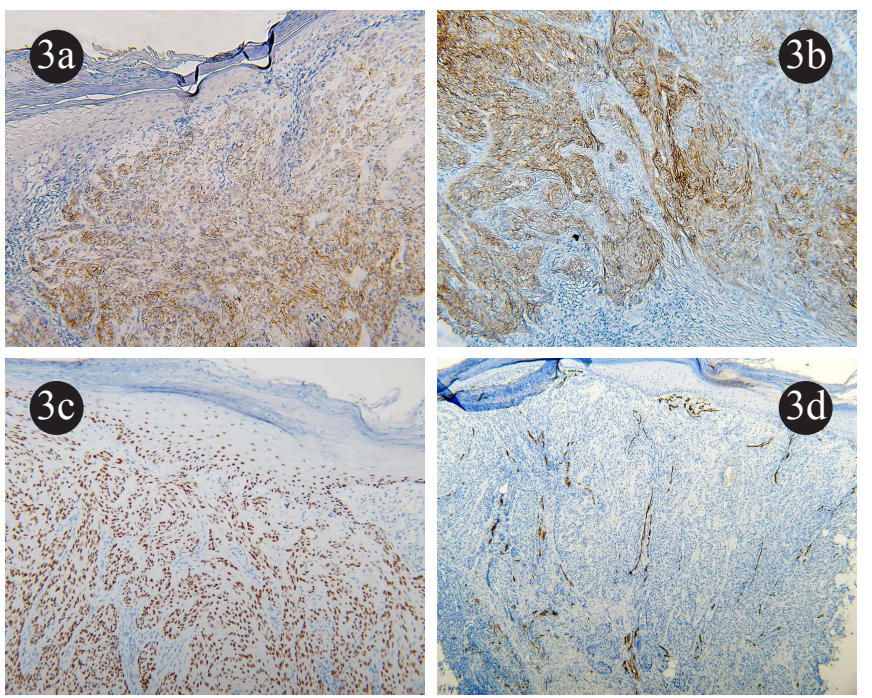

Fig. (3). Immunohistochemistry: (3a) Strong positive reaction for Cytokeratin AE1/AF3 in infiltrated neoplastic cells of epithelial origin in stroma (X20) (3b) P40 positivity is observed in epithelial cells (X20) (3c) Strong positivity for vimentin in spindle shaped cells (X20) (3d). Negative reaction for CD 34 cells (X20).

On the basis of microscopic and immunohistochemistry findings, the diagnosis of spindle cell carcinoma was confirmed.

\section{DIFFERENTIAL DIAGNOSIS}

Differential diagnosis for spindle cell carcinoma are angiosarcoma, leiomyosarcoma,fibrosarcoma, malignant melanoma, malignant fibrous histiocytoma, malignant peripheral nerve sheath tumor,kaposis sarcoma, leiomyoma, chondrosarcoma, osteosarcoma.Positive for smooth muscle actin and desmin differentiates sarcoma from spindle cell carcinoma. Melanomas can be differentiated from spindle cell carcinoma presence of melan-A and HMB-45 positive.

\section{DISCUSSION}

Squamous cell carcinoma (SCC) the malignant tumor which is most common with spindle cell carcinoma $(\mathrm{SpCC})$ also known as sarcomatoid carcinoma to be its highly malignant variant. It is a rare tumor and is biphasic. By biphasic it means that it is comprised of squamous cell carcinoma (in situ or invasive) as well as spindle cell carcinoma with sarcomatous appearance.

SpCC is also contemplated to be a neoplasm of monoclonal epithelial with the sarcomatous component which is obtained from squamous epithelium with divergent mesenchymal differentiation. The exact reason for occurence of $\mathrm{SpCC}$ is not known but has a strong association with history of smoking, excessive alcohol intake and radiation exposure [3]. In this case the patient had history of chewing tobacco from past 35 years.

As compared to females, $\mathrm{SpCC}$ is seen more in males (12:1 ratio) and mostly seen in 6-7 decades of life [5-8]. It is most commonly reported in larynx followed by different mucosal sites such as gingiva, tongue, nasal cavity and hypopharynx [2]. Most tumors are pedunculated or polypoid and less than 2 $\mathrm{cm}$ in size. The histological examination shows the carcinoma of squamous cell within the tumor [6]. Both squamous and spindle cells can be seen together in the appearance of, solid, fascicular and storiform appearance $[1,2,7]$. In this case, it is seen in fascicular pattern (Fig. 1). Immunohistochemical examination showed positive results for Cytokeratin $\mathrm{AE} 1 / \mathrm{AF} 3$, Vimentin and p40 which confirms the tumor to be spindle cell carcinoma and it showed negative results for CEA 
and $\mathrm{CD} 34[8,9]$.

The tumor is treated by wide local excision in the early stage. In the late stages, conservative treatment is done along with limited field irradiation. The treatment depends on how extensive the tumor has been spread out in the affected area. Surgery, dissection and radiotherapy is treatment option.

\section{CONCLUSION}

Spindle cell carcinoma ( $\mathrm{SpCC}$ ) or sarcomatoid carcinoma is highly malignant variant of squamous cell carcinoma which is rare. Early detection of the tumor can help in treating the tumor as it is not extensive at that stage while at late stages, the chances of invasion increases. Follow up is necessary in order to check for recurrence.

\section{AUTHORS' CONTRIBUTION}

All authors have equally contributed.

\section{CONFLICT OF INTEREST}

Declared none.

\section{ACKNOWLEDGEMENTS}

Declared none.

\section{REFERENCES}

[1] Anderson CE, Al-Nafussi A. Spindle cell lesions of the head and neck: An overview and diagnostic approach. Diagn Histopathol 2009; 15(5): 264-72.

DOI: $10.1016 /$ j.mpdhp.2009.02.009
[2] Thompson LDR. Squamous cell carcinoma variants of the head and neck. Curr Diagn Pathol 2003; 9: 384-96.

DOI: 10.1016/S0968-6053(03)00069-3

[3] Boamah H, Ballard B. A Case report of spindle cell (Sarcomatoid) carcinoma of the Larynx. Case Rep Med 2012; 2012: 1-4. DOI: $10.1155 / 2012 / 370204$

[4] Viswanathan S, Rahman K, Pallavi S, et al. Sarcomatoid (spindle cell) carcinoma of the head and neck mucosal region: A clinicopathologic review of 103 cases from a tertiary referral cancer centre. Head Neck Pathol 2010; 4: 265-75. DOI: $10.1007 / \mathrm{s} 12105-010-0204-4$

[5] Thompson LDR, Wieneke JA, Miettinen M, Heffner DK. Spindle cell (sarcomatoid) carcinomas of the larynx: A clinicopathologic study of 187 cases. Am J Surg Pathol 2002; 26(2): 153-70. DOI: 10.1097/00000478-200202000-00002

[6] Lewis JE, Olsen KD, Sebo TJ. Spindle cell carcinoma of the larynx: Review of 26 cases including DNA content and immunohistochemistry. Hum Pathol 1997; 28(6): 664-73. DOI: 10.1016/S0046-8177(97)90175-1

[7] Rath R, Das BK, Das SN, Baisakh M. Spindle cell carcinoma of maxilla: Histomorphological and immunohistochemical analysis of a case. J Oral Maxillofac Pathol 2014; 18(2): 256-61. DOI: 10.4103/0973-029X.140772

[8] Gerry D, Fritsch VA, Lentsch EJ. Spindle cell carcinoma of the upper aerodigestive tract: An analysis of 341 cases with comparison to conventional squamous cell carcinoma. Ann Otol Rhinol Laryngol 2014; 123(8): 576-83.

DOI: $10.1177 / 0003489414525337$

[9] Lewis JS. Jr. Spindle cell lesions-neoplastic or non-neoplastic?: Spindle cell carcinoma and other atypical spindle cell lesions of the head and neck. Head Neck Pathol 2008; 2(2):103-10. DOI: 10.1007/s12105-008-0055-4 